\title{
The Blessings and Curses of Big Time Football: One Perspective
}

\author{
Michael Martin \\ Colorado State University System
}

\begin{abstract}
Drawing from experiences as a leader at various universities, in this paper, the author discusses the blessings and curses of major intercollegiate athletic programs. Blessings include national attention, contribution to diversity, improved facilities, campus excitement, the ability to recruit top coaches and staff, and academic support. Curses include the considerable national attention, tighter scrutiny, misplaced priorities, a culture of dependency, decreases in faculty and staff morale, the potential for decrease athlete welfare, and a lack of competition. The author then offers potential solutions to these issues.
\end{abstract}

For more than four decades I have been involved in higher education and, in turn, involved in intercollegiate athletics. Over the past 10 years, I have led an institution with one of the poorest Division I-FBS athletic programs (New Mexico State University) and an institution with one of the wealthiest athletic programs in the country (Louisiana State University).

I have learned a great deal from both experiences. Here I share my observations based principally on my service at the "big time," highly financed LSU program. I offer a chancellor's view on both the blessings and curses of the powerhouse program, with specific attention on the football team.

\section{Blessings}

Unquestionably many good things come from having a winning "big time" football team. These include national attention, contribution to diversity, improved facilities, campus excitement, the ability to recruit top coaches and staff, and academic support.

\section{Enormous National Attention}

Major football programs offer universities national and, in some cases, international exposure. If used appropriately, this exposure enhances student recruiting and attracts donors. It brings tens of thousands of persons to campus on a Saturday and provides special opportunities to highlight academic programs and the campus

Martin is with the Chancellor's Office, Colorado State University System, Denver, CO. 
atmosphere to potential students, boosters, and donors. In the SEC, virtually every football game is televised. The identity created by this exposure results in millions of dollars in sales of university memorabilia. People around the world wear the colors of major American universities.

\section{Contribution to Diversity}

For many universities, it was their sports programs that affectively broke the color barrier. Even today sports programs bring a more diverse student body to campus. A visible community of diverse student athletes helps in recruiting nonathlete underrepresented minority students.

\section{Improved Facilities}

Successful sports programs help pay for improved campus facilities. For example, game day parking facilities, paid for in part by the athletic department, are available to provide parking for nongame day parking. Many college football stadiums house nonathletic offices, classrooms, and so on. At LSU, athletics generated funding for the creation of a state of the art academic advising center.

\section{Excitement on Campus}

A successful sports program can help build institutional pride and excitement. This aids in student recruiting, donor relations and, on occasion, faculty retention. I once had a faculty member, being pursued by another institution, request two season football tickets as a counter offer. It worked.

\section{You Can Afford the Best}

A competitive and financially successful football program can make a huge contribution to covering the costs for first-rate coaches, staff, advisors, and administrators. Excellent members of athletic departments can become excellent representatives for the larger university. When the Louisiana legislature considered allowing guns on campus it was an iconic coach who persuaded them it was (and is) a bad idea.

\section{Support for Academics}

At a few universities a share of athletics revenues are reallocated to directly support academic programs. At LSU \$7.5 million per year is transferred for this purpose above and beyond payment of tuition for scholarship athletes and support for the academic advising center.

\section{Curses}

As with many things in life, contemporary big time sports programs are not unambiguously good. There are curses that can accompany blessings. These include the considerable national attention, tighter scrutiny, misplaced priorities, a culture of dependency, decreases in faculty and staff morale, the potential for decrease athlete welfare, and a lack of competition. 


\section{Enormous National Attention}

When things go wrong, they go wrong on a very big stage. A sport team or program gone awry can sully the image of the larger university, as evidenced by the recent cases at Ohio State, Penn State, USC, Miami, and University of North Carolina, among others. The negative publicity and the cost of addressing NCAA violations and lawsuits can become daunting. In the case of a major NCAA rules violation, an institution often has to hire outside council, most of whom are forever authors of the very NCAA rules they are now charging to interpret and defend against - an interesting and lucrative circular industry indeed.

\section{Tight Scrutiny}

By their very "center stage" nature, the big time, big budget sports programs draw big attention, both from the NCAA and media. A student-athlete who misbehaves is the subject of attention rarely focused on a nonathlete student. A motorcycle "accident" by a coach grabs more attention than a similar accident by, say, an associate professor of history.

\section{Tail Can Wag the Dog}

Sometimes athletics, especially football, can get so much exposure and attention it overwhelms the larger institution. It becomes bigger than the institution itself. Coaches are superstars who take on celebrity status. During a particular football coach's contract negotiations, I was instructed to regularly update the governor on progress. At exactly the same time we were working to retain an outstanding, future national academy scholar, and there was no gubernatorial interest whatsoever in the latter contract negotiation.

Many, myself included, are troubled by the enormous influence TV and the money generated by TV contracts have on the missions and the standards of FBS universities. No university I know commits to providing "product" to ESPN, CBS, or Fox in their mission statement; yet, this has become a powerful force within and among universities. Under most conference TV contracts the broadcasters-not considerations for in-stadium fans or students-determine when games are played. We now have Thursday night games aimed at TV markets despite the fact that students and in-stadium fans are disadvantaged. If "Game Day" invites themselves to a campus, then parking, logistics, and schedules are dictated by ESPN.

\section{A Culture of Dependency}

Once a program is established, it becomes an engine of its own. The financial commitments-scholarships, coaches' salaries, travel, and recruiting, among othersbecome so large that it must be continually fed to succeed. It becomes too big to fail, and the consequences, financial and otherwise, are frightening.

\section{Faculty/Staff Morale}

During an extended period of public reductions in support for public universities and, in turn, stagnant faculty and staff salaries, the on-going explosion in athletic budgets and coaches' salaries can create real tensions on campus. These tensions 
are exacerbated when coaches, boosters, or students-athletes misbehave. Coaches get a large raise and bonus, while faculty and staff get none. The message, if not intentional, is that the academic side of the institution does not matter.

\section{Student Athlete Welfare}

When winning becomes ever more important, then coaches and others may push teams and, in turn student athletes, beyond what may be in their best long-term interest. The demands of playing in a big time football team can cause real conflicts with a commitment to academic progress and success. The physical wear and tear of football at the state college level is real and may have serious long-term, adverse health impacts.

\section{Lack of Real Competition}

With 35 sanctioned bowl games to fill, then 70 of 125 FBS team must win six games. This means that rich programs effectively buy two or three wins a year from poor programs, which sell losses to balance their budgets. This is a very cynical state of affairs. At worst, we sold games knowing our team had a miniscule chance of winning or even keeping the game close. At LSU, we bought two or three wins a year to pad the coach's record, provide him an extra five weeks of practice time to prepare for the bowl, and meet the "bowl bonus" provisions in the coaching staff's contracts. In most cases, bowl participation is a net financial loser. None of this is motivated by a spirit of true competition or about the student-athlete experience. It is largely about money on all sides.

\section{So What Should Be Done?}

Any expectation that we will somehow move back to an earlier more innocent, less money-driven time in college sports would be naïve in the extreme. Still, in my view, some redirection and reform is called for. Let me share a few recommendations.

- Reassert Primacy of Academic Center: While the NCAA is essential in the promotion and regulation of college sports, it is time for the academic side of the house to reassert influence over how athletics serves the larger mission of universities and should fit in the academic culture. Academic organizationsAPLU, ACE, AASCU - should jointly launch an initiative to redefine the roles and expectations of athletics and athletic departments. On a local level, academic leaders must fully assert sections 2.1.1 and 6.1.1 of the NCAA Manual.

- Accreditation Decisions: Regional accreditation agencies should include the finances and conduct of athletic departments in the review and reaccreditation decisions.

- Reduce the Number of Bowls: The number of bowl games (30) is, in my view, ridiculous. The vast majority is meaningless. Still, they serve to further reduce true competition and generally pad coaches' compensation.

- Revenue Sharing, Financial Leveling: A much more aggressive approach for leveling the financial playing field is overdue. This may mean capping total expenditures on intercollegiate athletics at, say, \$50 million per year per 
university and redistributing revenues above this level across institutions and/ or for investment in academic programs.

- Strike a Deal with Professional Sports: The "one and done" tradition in college basketball is the most egregious example of misusing college sports. But the NFL's raiding of football is only slightly better. While far from perfect, the approach of Major League Baseball serves as a starting point for developing a means for student athletes to make sufficient progress toward a degree and ensure that their time at a university is more than just an audition for the pros.

- Hold Coaches Truly Accountable: The implementation of Academic Progress standards (the APR) has provided a self-interest incentive for coaches to support the student side of student-athlete. Still, we have too many cases when coaches fail in other ways-break rules or embarrass an institution-but continue on their coaching career by changing institutions. A lawyer violates standards and she or he is disbarred and thus expelled from the legal profession. Something similar should be implemented for coaches. Some form of licensure or certification should help ensure that a coach does not leave a wake of NCAA violation behind as he simply moves on to violate again. The NCAA bans student-athletes for misconduct but fails to hold coaches to comparable standards. Since the NCAA will not, then universities collectively should.

\section{Summary}

Maximizing blessings and minimizing curses is a tricky business in with "big time" programs. University leaders must confront a wide range of outside, and some inside, forces. The time has come in my view for collective, unified action. 